Journal of Advanced Research in Materials Science

Journal homepage: www.akademiabaru.com/arms.html ISSN: 2289-7992

\title{
Solar Collector Application using Nanofluid in Thermosyphon
}

\author{
Muhammad Mahmud Jamil ${ }^{1}$, Nor Azwadi Che Sidik ${ }^{2,}$, Siti Nurul Akmal Yusof ${ }^{1}$ \\ Department of Mechanical Engineering, Nigerian Defence Academy, Kaduna, PMB 2109, Kaduna, Nigeria \\ 2 Malaysia - Japan International Institute of Technology (MJIIT), University Teknologi Malaysia,Jalan Sultan Yahya Petra,54100 Kuala Lumpur, \\ Malaysia
}

\begin{abstract}
The development of solar collectors for application in water heating, agricultural product drying, heat engines have attracted attention of scientist. Energy usage is inevitable, as renewable energy is becoming more popular and environmentally accepted. In this study, the concept of flow inside the collector tube is mainly by natural convection as a heat transport in the domain. The objectives of this study are to investigate the heat transfer enhancement of titanium water nanofluid (TiO2-water nanofluid) and the effect of inclination angle of a single tube evacuated solar collector in a closed thermosyphon. TiO2-nanoparticles was dispersed into the based fluid (water) using volume fraction concentrations of $0.05-1 \%$. For the geometrical tilt angle, three different inclination angles of $30^{\circ}, 45^{\circ}$ and $60^{\circ}$ for a constant heat flux of $500 \mathrm{~W} / \mathrm{m} 2$ corresponding to relative solar irradiance absorb by a single tube collector. Moreover, due to inevitable coupling of the flow with temperature and low velocity profile related with the flow, the velocity and pressure coupling was computed using PISO scheme. The present result demonstrated that addition of TiO2nanoparticles produced a reasonable Heat transfer enhancement in comparison with conventional heat transfer fluid (water). Heat transfer enhancement increases with increasing volume fraction of TiO2-nanoparticles. Nusselt number enhancement was common at inclination angle of $30^{\circ}$. Therefore, enhancement of $25.6 \%$ was observed at a volume fraction of $0.1 \%$ and it was noting that increases the volume fraction will result in a more than $100 \%$ enhancement to water. The influence of inclination angle has indicated that the maximum Nusselt number and velocity are present at angle of $30^{\circ}$. Hence, inclination angle is an effective parameter for nanofluid filled in single tube evacuated solar collector.
\end{abstract}

Keywords:

Solar collector; thermosyphon;

nanofluids

Copyright @ 2020 PENERBIT AKADEMIA BARU - All rights reserved

\section{Introduction}

Renewable energy application gives rise to marketable energy by converting natural phenomena into useful forms of energy. Solar energy technologies are non-polluting to environment and offer reduction of greenhouse gases effect. Therefore, another ability of renewable energy technology is creation of job opportunity. Mostly, new technologies bring about different market activities. In the case of solar collectors, the job opportunity depends on the production of the collector and installation work.

* Corresponding author.

E-mail address: azwadi@utm.my (Nor Azwadi Che Sidik)

https://doi.org/10.37934/arms.65.1.115 
There are many types of renewable energy sources, which include biofuel, wind, tide, hydrogen, geothermal that can also be use in place of fossil fuels. The issue of selection of which one is suitable will be based on availability, economic, environmental and safety issue. Considering the abundance and environmental safety of sunlight, it is generally believed that solar energy is a better alternative energy process. There is currently high demand of solar collectors, more especially the water-in-glass evacuated tube solar collector (ETSC) [1-3].

Solar energy collectors are mediums generally design to collect and absorb the solar radiation. The solar radiation absorb is converted into heat by the collector devices which is eventually transfer into the working fluid of the system usually water and air. The main components of any thermal related solar system are solar collectors. Basically, there are two types of solar collectors: stationary or non-concentrating and sun tracking or concentrating [4]. The stationary types are characterized by having same area for intercepting and for absorbing solar radiation, while concentrating type use concave reflecting surfaces to intercept and focus the sun's beam radiation to a smaller receiving area, thereby increasing radiation. Evacuated tube solar collector (ETSC) and Flat plate solar (FPC) collectors are the most common and widely use solar collectors [5-8].

Evacuated tubes are the type of solar collectors that are more efficient and operate at higher temperature than Flat plate collectors. This device was developed by Owens-Illonois and is called Sunpak solar collector. It can use air or liquid as its working fluid (heat transfer fluid) [9-14]. Generally, evacuated tubes are made of two layers of glass tubes; borosilicate glass is identified as the ideal for evacuated tube collectors due to its high chemical and thermal shock resistance. The outer surface layer of the glass collects the solar radiation with little dispersion while the inner layer of the glass is coated with standard solar coating techniques which results in better solar radiation absorption with minimum reflection.

Kim and Seo [4] studied experimentally and numerically the thermal performances of four different shaped absorbers for U-pipe evacuated solar collector. They found that the used of copper plate material welded with pipe gives better performance when the beam insolation, shade and diffuse irradiation were taken into consideration. Another study for thermal performance of U-pipe also was done by Gao et al., [9]. They reported that evacuated solar collector generally works better in a cold climate as compared to flat plate solar collectors and also associated with low heat loss advantage. However, the thermal efficiency of the collector will not increase certainly with increasing length. Thus, optimal design of mass flow rate for higher thermal efficiency is necessary for UpEST collector.

The major application of evacuated tube solar collector is water heating but it can also be used for generation of hot air. Ashish et al., [13] studied experimentally a one ended evacuated tube solar collector using air as working fluid for the generation of hot air. Four different analyses were made with reflector employed and without reflector respectively. Their results show that the used of reflector will certainly increase the evacuated tube collector performance. Figure 1 below shows the schematic diagram of all glass evacuated air solar collector.

Solar thermal utilization is one of the methods to improve the efficiency of the solar collector. Solar collectors utilizing thermosyphon flow to transport energy from collector to the store are one of the simplest and most widely used solar collection devices. Apart from that, the use of nanofluid as a working medium is the best option to enhance the thermal conductivity since the previous working mediums (air and liquid) has low thermal conductivity. Nanofluids are a mixture of liquid and nanoparticles size [. These fluids prepared by dispersing nanoparticles size $10 \mathrm{~nm}-200 \mathrm{~nm}$ in different base fluids. Nanofluid has rendered thermo physical properties such as thermal conductivity, convective heat transfer coefficient compared with other fluids [15-18]. 


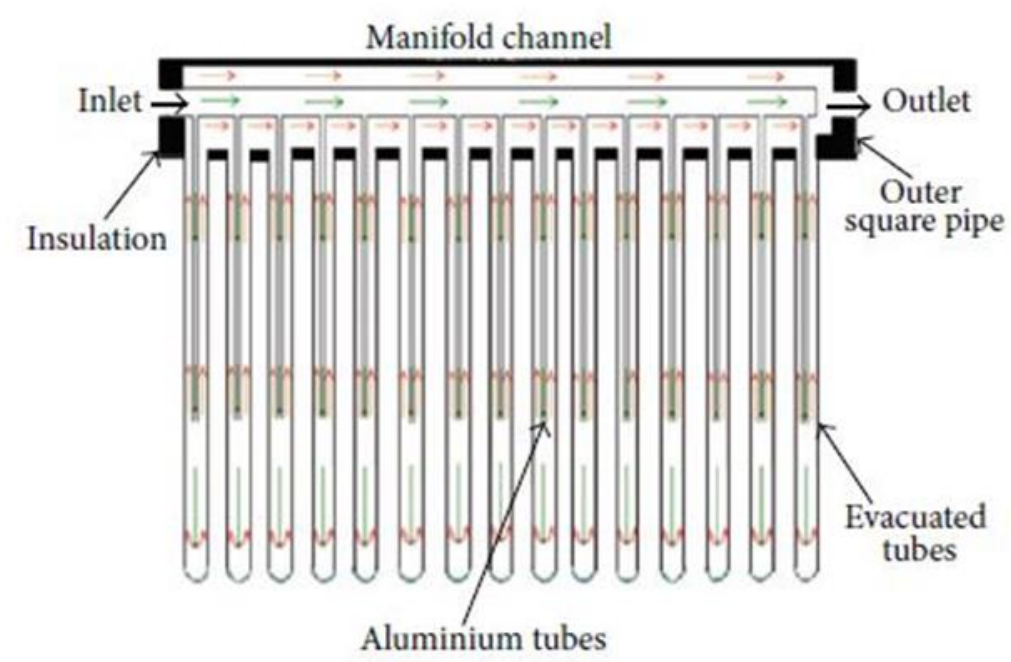

Fig. 1. Schematic diagram of evacuated air solar collector [11]

Mahendran et al., [19] determined the efficiency of an evacuated tube solar collector using water-based titanium oxide ( $\mathrm{TiO}_{2}$ ). In their study, the effect of clear sky and cloudy day against the time and the solar insolation was analysed extensively. They reported that the temperature enhancement of nanofluid is about $19 \%$ higher than that of water. The maximum efficiency of the collector system using $\mathrm{TiO}_{2}$ is 0.73 as compared to water which is 0.53 . Zainab et al., [20] carried out the study to investigate the impact of alumina nanoparticles suspended in water flowing in flat solar collector. They reported that adding 3\% solid nanoparticles to water improves heat transfer by (54\%).

Experimental studied of solar collector application using nanofluid in thermosyphon have been done by previous researchers [18, 21-26]. Zhen et al., [21] possibly among the first who considered tubular evacuated high temperature air solar collector of an open thermosyphon using nanofluid. Lin et al., [18] investigated an indoor experiment of high temperature open thermosyphon in evacuated tubular solar collector. The experimental set-up is made of condenser and evaporator in the collector through which the open thermosyphon effect is operated. They reported that the use of $\mathrm{CuO}$ nanofluid has remarkably improve the convective heat transfer coefficient in the open thermosyphon. The wall temperature increases significantly using nanofluid and decreases using water.

To the best of author's knowledge, study on solar collector application using nanofluid in a closed thermosyphon has not been reported yet. Thus, the main objectives of this study are to investigate the heat transfer enhancement of titanium water nanofluid (TiO2-water nanofluid) and the effect of inclination angle of a single evacuated tube solar collector (ETSC) in a closed thermosyphon. The numerical analysis is based on Pressure Implicit with Splitting of Operator (PISO) method. The computations were mainly performed for 3D dimensional shape.

\section{Governing Equation}

\subsection{Description of the Problem and Conservation Equation}

In this study, a three-dimensional single tube evacuated solar collector was simulated out of the standard 21 or 36 tubes available in the market. The tube is connected to a storage tank of $150 \mathrm{~L}$ and the tube length and diameter were $1420 \mathrm{~mm}$ and $34 \mathrm{~mm}$ respectively. Figure 2 shows a schematic of ETSC with tank showing the symmetry of the simulated single tube at the middle. Figure 3 shows the model of a single tube which is considered as symmetry from the original collector dimensions. Both 
tank and tube were taken as symmetry of the whole set up so as to minimize the generation of more mesh which reduce the computational time.

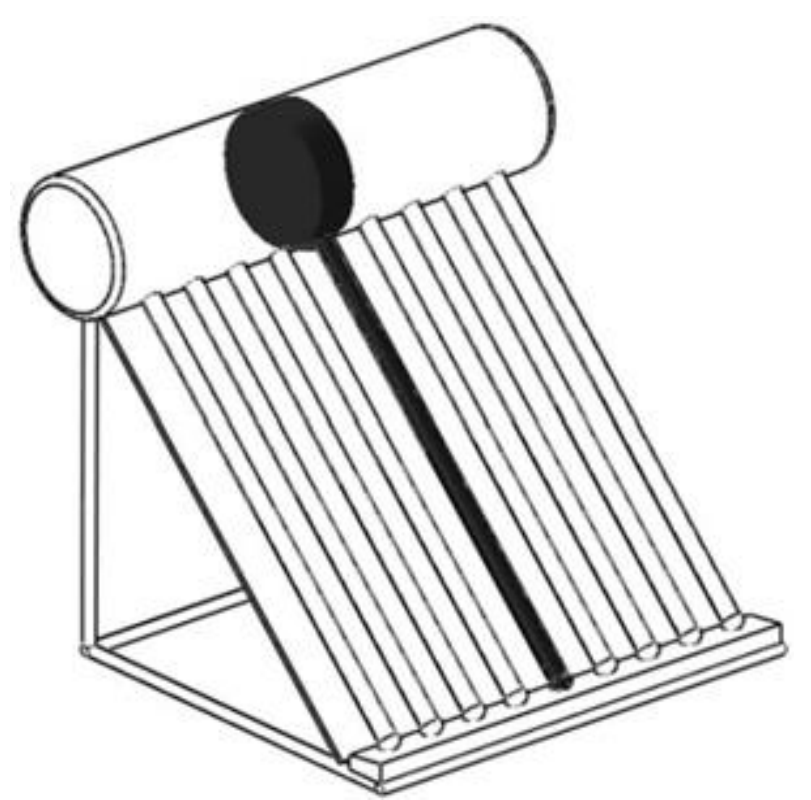

Fig. 1. Schematic of a collector model for single tube and reservoir tank [27]

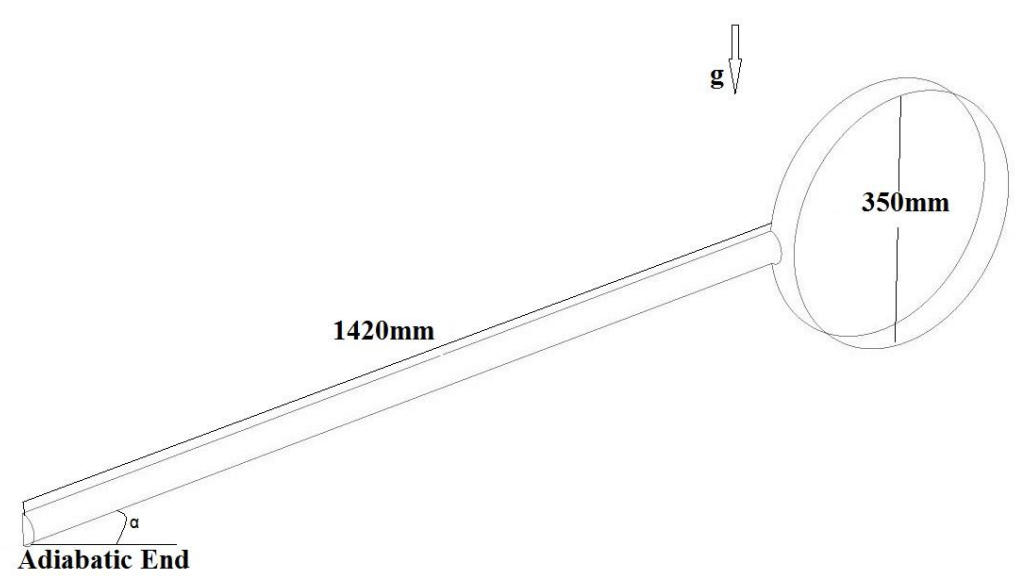

Fig. 3. 3D Model of single end evacuated tube solar collector

The governing equations to be considered are the time-averaged compressible continuity, momentum and energy equations.

$\frac{\partial u}{\partial x}+\frac{\partial v}{\partial y}+\frac{\partial w}{\partial z}=0$

$\rho\left(\frac{\partial u}{\partial t}+u \frac{\partial u}{\partial x}+v \frac{\partial u}{\partial y}+w \frac{\partial u}{\partial x}\right)=-\frac{\partial p}{\partial x}+\mu\left(\frac{\partial^{2} u}{\partial x^{2}}+\frac{\partial^{2} u}{\partial y^{2}}+\frac{\partial^{2} u}{\partial z^{2}}\right)-\rho g_{x} \beta\left(T-T_{r e f}\right)$ 


$$
\begin{aligned}
& \rho\left(\frac{\partial v}{\partial t}+u \frac{\partial v}{\partial x}+v \frac{\partial v}{\partial y}+w \frac{\partial v}{\partial x}\right)=-\frac{\partial p}{\partial y}+\mu\left(\frac{\partial^{2} v}{\partial x^{2}}+\frac{\partial^{2} v}{\partial y^{2}}+\frac{\partial^{2} v}{\partial z^{2}}\right)-\rho g_{y} \beta\left(T-T_{r e f}\right) \\
& \rho\left(\frac{\partial w}{\partial t}+u \frac{\partial w}{\partial x}+v \frac{\partial w}{\partial y}+w \frac{\partial w}{\partial x}\right)=-\frac{\partial p}{\partial z}+\mu\left(\frac{\partial^{2} w}{\partial x^{2}}+\frac{\partial^{2} w}{\partial y^{2}}+\frac{\partial^{2} w}{\partial z^{2}}\right)-\rho g_{z} \beta\left(T-T_{r e f}\right) \\
& \left(\frac{\partial T}{\partial t}+u \frac{\partial T}{\partial x}+v \frac{\partial T}{\partial y}+w \frac{\partial T}{\partial x}\right)=\frac{k}{\rho c_{p}}\left(\frac{\partial^{2} T}{\partial x^{2}}+\frac{\partial^{2} T}{\partial y^{2}}+\frac{\partial^{2} T}{\partial z^{2}}\right)
\end{aligned}
$$

\subsection{Boundary Conditions}

The boundary conditions assumed in this numerical approach were taken based on the physical phenomenon considered in an evacuated tube solar collector (ETSC). Based on the reported literatures the boundary conditions were considered in terms of the circumferential heat flux and the adiabatic zones of the domain [7, 28]

However, the tube is divided into two: the top part and bottom part based on the symmetry considered in the geometry. The heating is only applied on the top part where as the bottom part is unheated throughout this study. This was taken in view of the general benchmark studies. Top part received about $57 \%$ or $50 \%$ of the solar radiation whereas the bottom received less unless otherwise with the use of a reflector under it.

In this study, the initial conditions considered are as follows:

I. All temperatures are assumed to be equal to $300 \mathrm{~K}$

II. All velocities are equal to zero

III. The flow is laminar using constant properties except for Density-Boussinesq approximation.

\subsection{Heat Transfer and Flow Parameters in ETSC}

\subsubsection{Heat transfer coefficient}

The heat transfer from an inclined tube surface may be evaluated in form of a linear correlation given by Newton, between the heat transfer rate $Q$ and the temperature difference between the surface and the ambient.

$Q=\bar{h} A\left(t_{s}-t_{a}\right)$

Where $\bar{h}$ is termed the overall convective heat transfer coefficient and $\mathrm{A}$ is the total area of the inclined heated surface. The coefficient $\bar{h}$ depends on the flow configuration, fluid properties, dimensions of heated wall and generally also on the temperature difference, because the dependence of $\mathrm{Q}$ on $\left(t_{s}-t_{a}\right)$ is not linear. Moreover, the given equation is useful in convection processes in which $\mathrm{h}$ can be evaluated. Since the fluid motion becomes zero at the surface, due to the no-slip condition, which demands that there will be no relative motion between the surface and fluid immediately adjacent to it, the heat transfer from the heated surface to the fluid in its immediate vicinity is by condition. It is therefore by conduction, given by Fourier's law as: 


$$
Q=-k A\left(\frac{d t}{d y}\right)
$$

Where the gradient is evaluated at the surface, $y=0$, in the fluid, $\mathrm{k}$ being the thermal conductivity of the fluid. However, the above equation implies the effect of the natural convection flow would be on the temperature gradient at the surface, since the remaining parameters would remain essentially unaltered. Therefore, it is important to determine the gradient because it depends on the flow, temperature field and fluid properties.

\subsubsection{Nusselt number (Nu)}

The heat transfer coefficient $\bar{h}$ defined above, is obtained from the above relationship through integration over the entire area. Both local and average heat transfer coefficient are generally given in terms of the dimensional parameter, Nusselt number. In addition, for natural convection Nusselt number is dominated by Grashof Number whereas in forced convection is dominated by Reynolds number, the average and local Nusselt numbers are given as follows:

$\overline{N u}_{D}=\frac{\bar{h}_{D} D}{k}$

Where $D$ is the diameter of the tube and hence, represents the characteristic dimension.

\subsubsection{Grashof number (Gr)}

Grashof number is defined as a ratio of a buoyancy force and the viscous force. In the case of evacuated tube solar collector, the temperature is not known, the uniform flux being the only physical quantity known from the heat input. Meanwhile, to simplify the case in the heated surface, sparrow and Gregg [29] introduced a modified Grashof number $G r_{x}^{*}$ defined as:

$G r_{x}^{*}=g \beta q x^{4} / k v^{2}$

The temperature difference in the conventional Grashof Number $G r_{x}$ is, therefore, replaced by $\mathrm{qx} / \mathrm{k}$. Also, $G r_{x}$ is given in terms of the inclination angle of the collector.

$$
G r_{D}=\frac{g \beta \cos \theta \Delta T D^{3}}{v^{2} k}
$$

\subsubsection{Reynolds number (Re)}

Reynolds number is another dimensional parameter that plays role in almost any flow, be it laminar flow or turbulent flow. In this study, the use of Re is not of much significant because the flow is natural convection, therefore, is associated with low velocity flow in the enclosure and dominated by Gr. Reynolds will only be important an external flow occur. The equation below given in terms of the mass flow rate of the system can be used to calculate the Reynolds number. 
$R_{e}=\frac{4 \dot{m}}{\mu \pi d}$

Where $\dot{m}$ and d represents the mass flow rate and the tube diameter respectively.

\subsubsection{Rayleigh number $(R a)$}

Rayleigh number is a dimensional parameter in natural convection heat transfer that comprises the product of Grashof number and Prandl number respectively.

$$
\begin{aligned}
& R a_{D}=G r_{D} \operatorname{Pr} \\
& R a_{D}=\frac{\beta g\left(T_{s}-T_{a}\right) D^{3}}{v^{2}} \operatorname{Pr} \\
& R a_{D}=\frac{\beta g\left(T_{s}-T_{a}\right) D^{3}}{v^{2}} \frac{v}{\alpha} \\
& R a_{D}=\frac{\beta g\left(T_{s}-T_{a}\right) D^{3}}{v \alpha}
\end{aligned}
$$

Where $\alpha$ and $\beta$ represents the thermal diffusivity and coefficient of thermal expansion of the fluid.

The criterion for determination of laminar or turbulent transition flow in natural convection heat transfer is expressed in terms of Rayleigh number given as:

$$
\begin{aligned}
& R a_{D} \leq 10^{9} \text { Laminar flow } \\
& R a_{D} \geq 10^{9} \text { Turbulent flow }
\end{aligned}
$$

\subsubsection{Velocity field}

The measurement of velocity in a natural convection flow is complex, due to the lower magnitude of velocity. Meanwhile, the complexity of determination of velocity magnitude arises as a result of continues variation of temperature and density which generates the flow. The unavoidable temperature fields that exists in the flow also attributes to the difficulty of velocity measurements. To estimate the maximum velocity to be generated in the flow, the convective velocity is coupled with density difference and temperature difference [30].

$$
V_{c}=\sqrt{g \beta L\left(T_{S}-T_{a}\right)}
$$

Where $\mathrm{L}$ is the characteristic dimension of the body. Thus, $V_{c}$ may be employed for the dimensionalization of velocities that occur in the flow, since it represents the maximum velocity that may be expected to arise. 


\subsubsection{Temperature and flow visualization}

The measurement of temperature at the surface of the body generating the flow is very important since constant heat flux is considered as the only heat input. Most of the temperature measurements in the fluid would be restricted to the flow inside the region, although sometimes the wall and ambient temperatures have to be taken outside the flow region. The measurements can be related to heat transfer rate by determining the temperature gradient at the surface.

However, the thermal region in ETSC can be obtained through flow visualization of thermal stratification region inside the reservoir tank. The stratification is visualized at the bottom of the reservoir tank where the temperature at different depth in the tank varies due the variation of fluid density with temperatures. Cold fluid is denser than warm fluid hence the flow structure can be visualized.

\subsection{Numerical Solution}

The solution method used for pressure-velocity coupling of the discretized equations is pressure implicit with splitting of operators (PISO) algorithm. This method was formulated by Issa [31] as an extension of SIMPLE method algorithm. In addition, PISO algorithm was initially developed to solve for the non-iterative unsteady flow solution for compressible flow. The main divide between this method and the earlier methods like SIMPLE algorithm was the enhancement in the discretized equations with two correction steps.

\subsection{Thermophysical Properties of Nanofluid}

Nanofluid is a mixture of liquid (based fluid) and nanoparticles. Generally, nanotechnology has a role in promoting the advancement of the current technology. This type of fluids possesses some thermo physical properties that aid in enhancement of the nanofluid performance over convectional type of fluid (water). The thermophysical property of nanofluid includes density, specific heat, thermal conductivity and viscosity. In this study $\mathrm{TiO} 2$ nanoparticles is selected. Thermophysical properties oc based fluid and $\mathrm{TiO} 2$ nanoparticles are listed in Table 1.

Table 1

Thermophysical properties of base fluids and $\mathrm{TiO} 2$ nanoparticles

\begin{tabular}{llll}
\hline Thermophysical properties & Water & Ethylene glycol & TiO2 \\
\hline Density , $\rho(\mathrm{kg} / \mathrm{m} 3)$ & 998.2 & 1113.2 & 4175 \\
Specific heat capacity Cp $((\mathrm{J} / \mathrm{kgK})$ & 4182 & 2,090 & 773 \\
Thermal conductivity , $\mathrm{k}(\mathrm{W} / \mathrm{mK})$ & 0.6 & 0.253 & 8.4 \\
Coefficient of volume expansion, $\beta$ 1/k & 0.00021 & - & $0.9 \mathrm{E}-5$ \\
\hline
\end{tabular}

\section{Results}

\subsection{Sensitivity Test of Model and Validation}

For grid sensitivity test, different meshes were tested with different elements sizes. The selection of a steady mesh was conducted based on the changes of temperature and velocity at the opening of the tube. However, a grid of 586,275 elements was chosen since there is stability in the temperature changes and the flow is almost fully developed in the tank reservoir as shown in Figure 4. In view of the computational time, the $4 \mathrm{~mm}$ size was preferred ahead of the $3 \mathrm{~mm}$ and $2 \mathrm{~mm}$ respectively. The convergence criteria of the simulation were tested based on the time discretization 
criteria and the effects of residuals on the end result of the simulation. Hence, it was found that the residual is not considerate in this type of study as it is considered transient simulation, the timedependent of the study make it more difficult to reach to steady state condition. Therefore, low residuals are enough to ensure a good result with a time step reduce to one order of magnitude of the smallest cell of the mesh according to the Courant-Friedrichs law (Lewy condition).

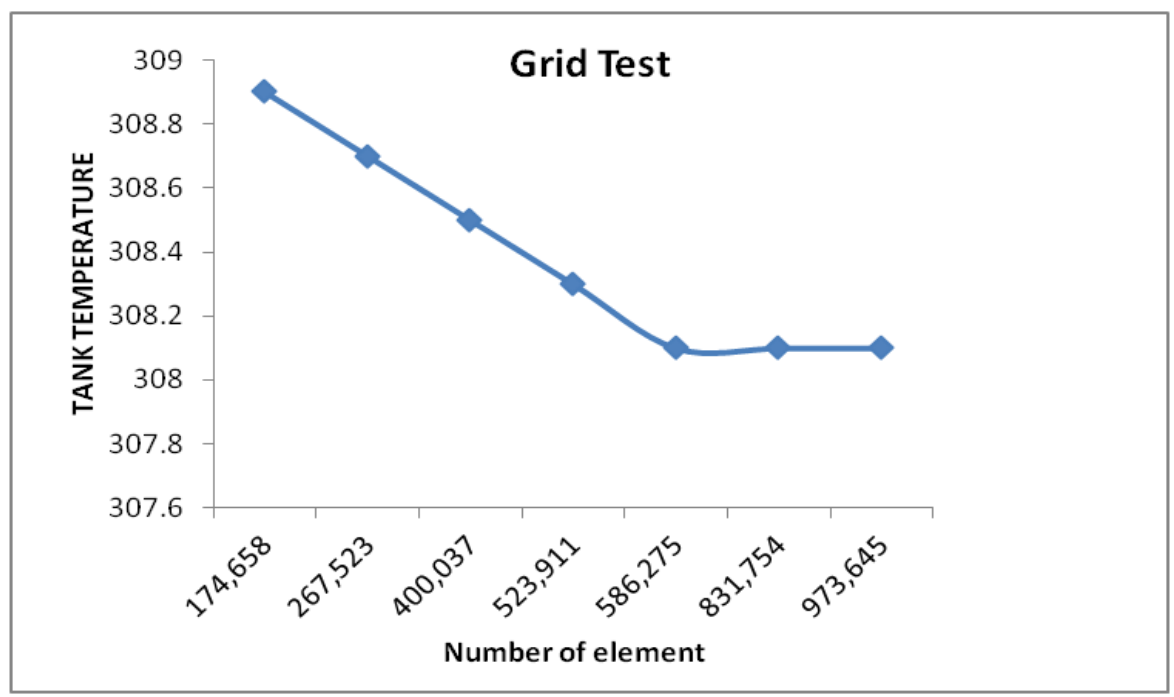

Fig. 4. Grid sensitivity test of Number of elements against tank temperature

The model validation was performed based on the experimental work reported by Budiharjo et al., [3]. Comparisons were made qualitatively and quantitatively in terms of the reported values of maximum velocity and maximum temperature in the tank. A maximum temperature of approximately $308 \mathrm{~K}$ was obtained which is the same as the value reported in the experiment. All validated results were computed based on the benchmark parameters using 45 degree geometry angle and $500 \mathrm{~W} / \mathrm{m}^{2}$ heat flux respectively. Figure 5 shows the velocity magnitude changes along the tube positions near the opening for the in-flow and out-flow of the velocity. Furthermore, it is believed that the simulation and the experiment are in good agreement considering the nature of the maximum velocity at the tube opening between the inlet and outlet of the fluid.

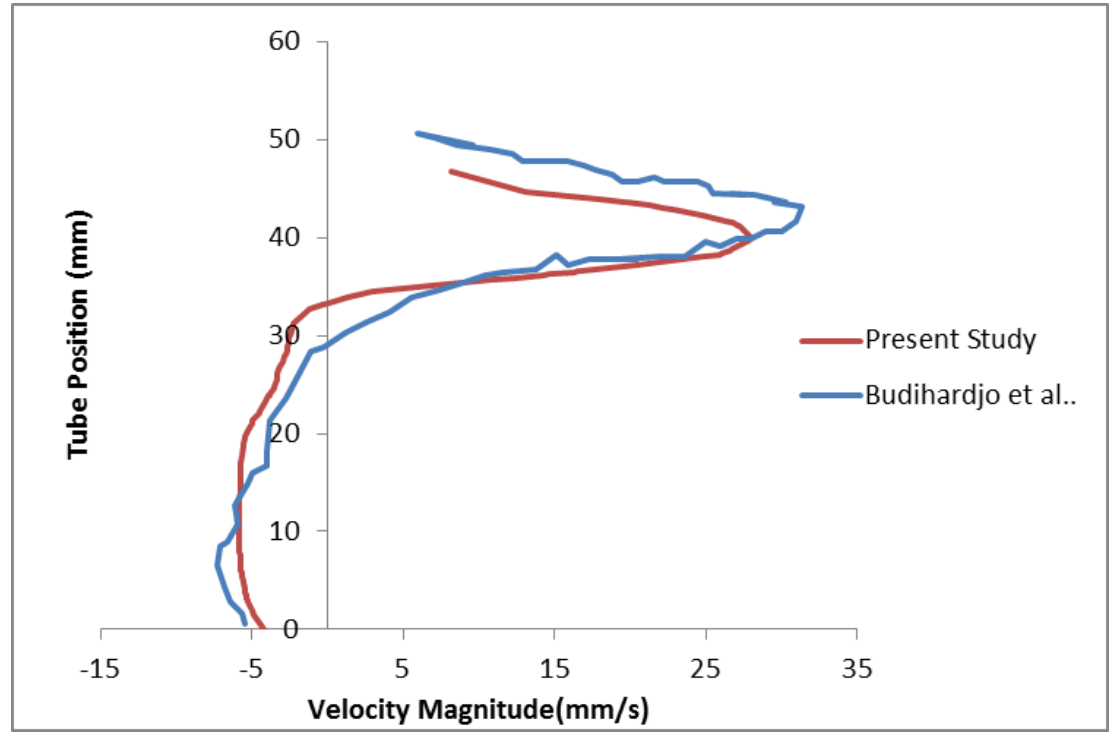

Fig. 5. Validation of velocity magnitude at the tube opening 


\subsection{Transient Effect of TiO2-Water Nanofluid on the Collector Performance}

The transient velocity profile of TiO2-water nanofluid with respect to simulation time of 3600s for volume fraction of $\phi=0.1 \%$ is presented. As can be realized, the velocity is analyzed using three different inclination angles of $30^{\circ}, 45^{\circ}$ and $60^{\circ}$ of the ETSC. Meanwhile, in this study the maximum average velocity decreases as time increases due to the increase in secondary circulation in the tube. Thus, it is also due to the existence of dimensional number called Grashof number which accelerates or retards the flow behavior. Mostly, Buoyancy force and viscous force are two common forces that resulted in flow in the boundary layer regime in natural convection flow such as ETSC. The velocity profile values were recorded for every 400 s of simulation time.

However, the existence of Gr number contributed to the flow configuration from the nanofluid properties used. As Gr value is large, the buoyancy force dominates whereas for small Gr value viscosity dominates. The value of $\mathrm{Gr}$ of nanofluid at $\phi=0.1 \%$ is in the order of $10^{5}$ which is higher with respect to the mode of flow which is laminar. It can be observed that buoyancy force results in higher velocity magnitude and increase the boundary layer flow. The variation of collector inclination angle using volume fraction of $\phi=0.1 \%$ indicated decrease in inclination angle which results in higher value of velocity magnitude. Conversely, increase in inclination angle of collector with respect to time results in decrease in velocity magnitude.

These results deduce that the velocity magnitude of nanofluid at lower volume fraction has shown remarkable discrepancies in velocity values of inclination angles of $30^{\circ}, 45^{\circ}$ and $60^{\circ}$ respectively. As shown in Figure 6 . Angle $30^{\circ}$ has shown higher value of velocity compared to $45^{\circ}$ and $60^{\circ}$ due to higher buoyancy force acting in the tube enclosure than the viscosity force.

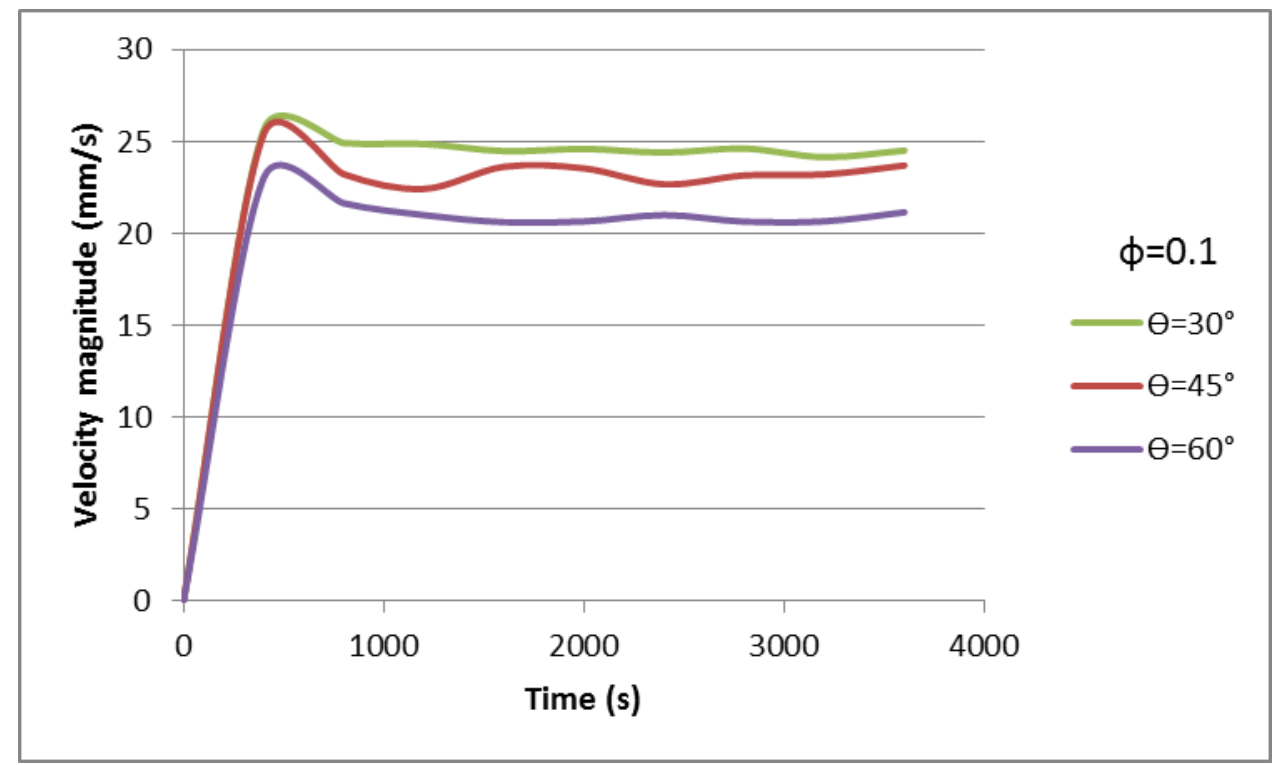

Fig. 6. Transient effect of nanofluid across the tank reservoir

Figure 7 shows comparison of velocity profile of nanofluid at volume fraction of $\phi=0.1$ and base fluid over a time period of $3600 \mathrm{~s}(1 \mathrm{hr})$ by using angle 45 . The relationship demonstrates enhancement of velocity magnitude of TiO2-water nanofluid over water. As aforementioned, nanoparticles have indicated increase in the heat transfer performance compared to the base fluid. Thus, it can be signal to say that increase in the volume fraction of the nanoparticle increase the velocity magnitude due to higher value of buoyancy force to viscosity ratio in the fluid. Constant change in the surface and fluid temperature changes the fluid flow characteristics. Higher 
temperature difference results in less heat transfer performance and small value of velocity magnitude. As shown in figure, the volume concentration of nanoparticles shows higher value of velocity magnitude due less temperature difference as compared to the base fluid.

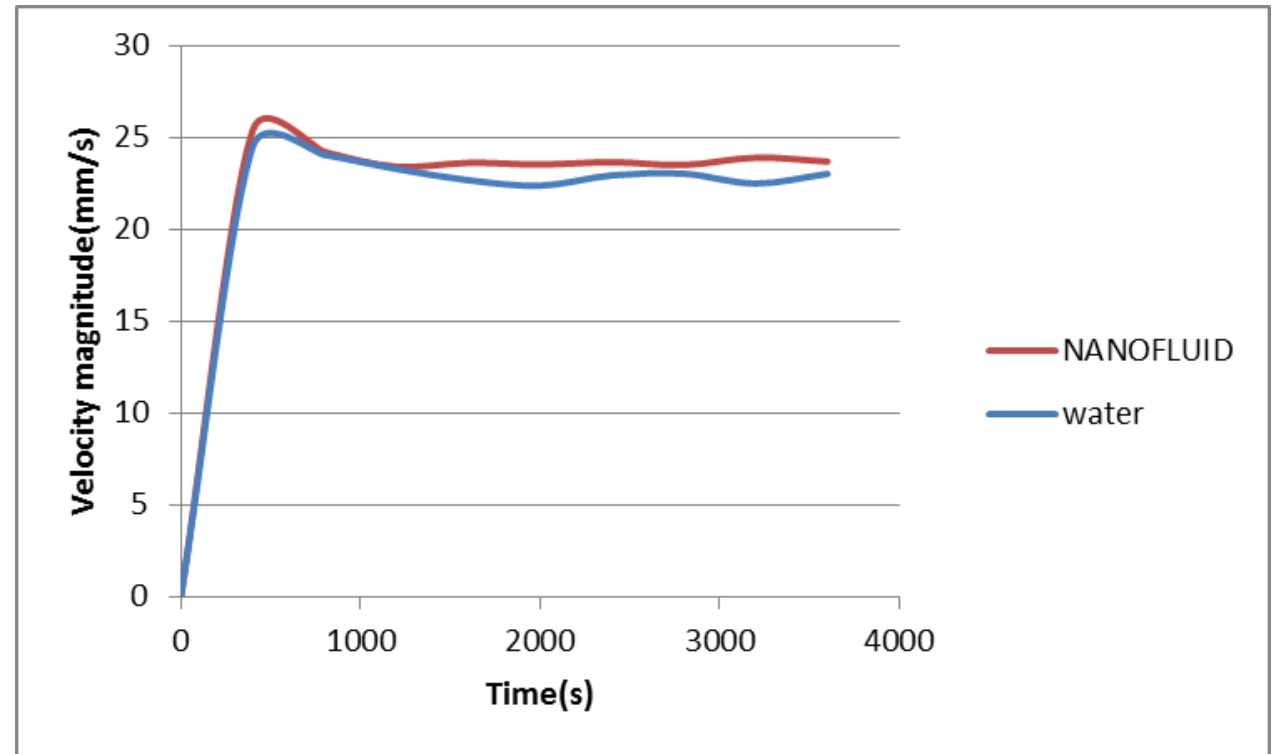

Fig. 7. Comparison of transient effect between nanofluid and water at inclination angle of 45

\subsection{Effect of Variation of Local Nusselt Number along the Heated Part}

The variation of local Nusselt number along the heated wall at different inclination angle for volume fraction of $\phi=0.1$ is given in Figure 8 . From the figure, it can be seen that the Nusselt number tends to decrease over the half of the heated wall. The results show that the inclination angle affects the heat transfer performance of the collector. As can be seen from the figure, inclination angle $30^{\circ}$ indicates higher value of Nusselt number, whereas inclination angle of $60^{\circ}$ shows lower values of both Nusselt number along the heated part. The result is in line with other literatures that found that the inclination small angle of have the highest value of Nusselt number over the heated wall [32].

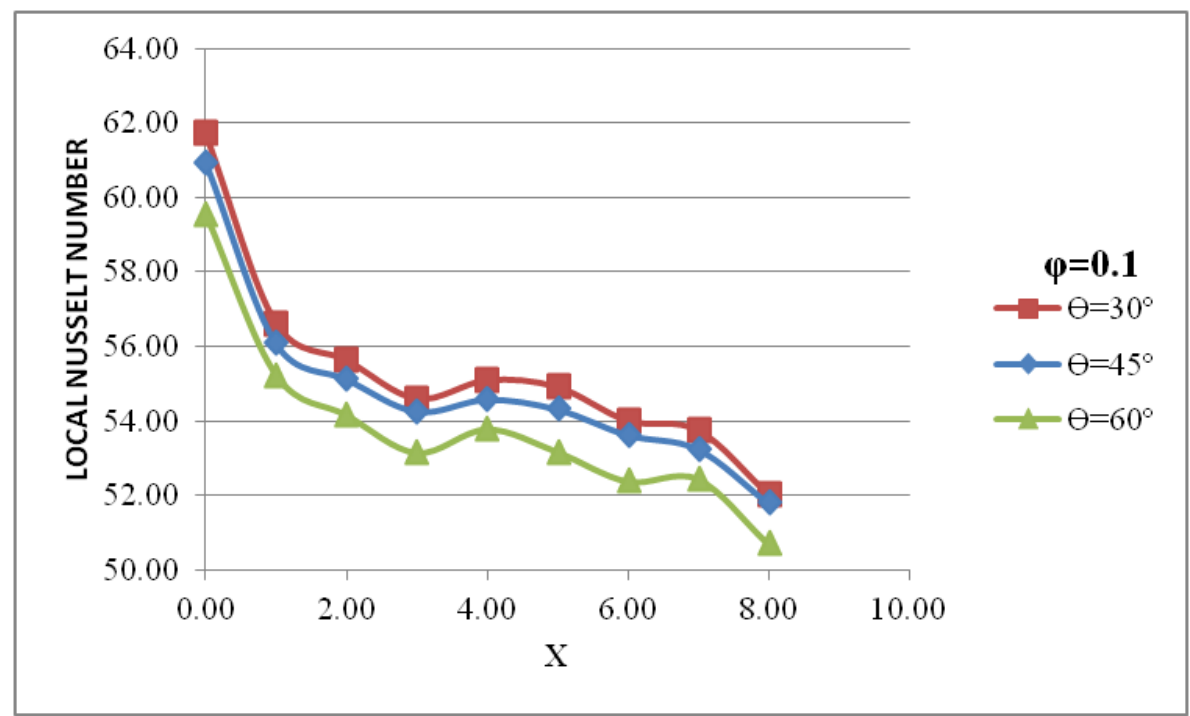

Fig. 8. Comparison of local Nusselt number at $\phi=0.1$ volume fractions along the heated wall for $30^{\circ}, 45^{\circ}$ and $60^{\circ}$ 


\subsection{Effect of Inclination Angle on Mean Nusselt Number of Collector}

The variation of mean Nusselt number with volume fraction for different inclination angles of $30^{\circ}$ to $60^{\circ}$ is given in Figure 9. For all values of inclination angles, the volume fraction increases the mean Nusselt number. It is seen for all angles that increasing inclination angle decreases the mean Nusselt number with respect to volume fraction concentration. These are cause as a result of weak secondary recirculation in the tube and thus, mean Nusselt number decreases at higher inclination angles. In addition, it can be observed that addition of $\mathrm{TiO}_{2}$ nanoparticles has represented the most influence at angle of $30^{\circ}$. Conversely, lowest mean Nusselt number is obtained at $60^{\circ}$ which is the highest angle considered in this study.

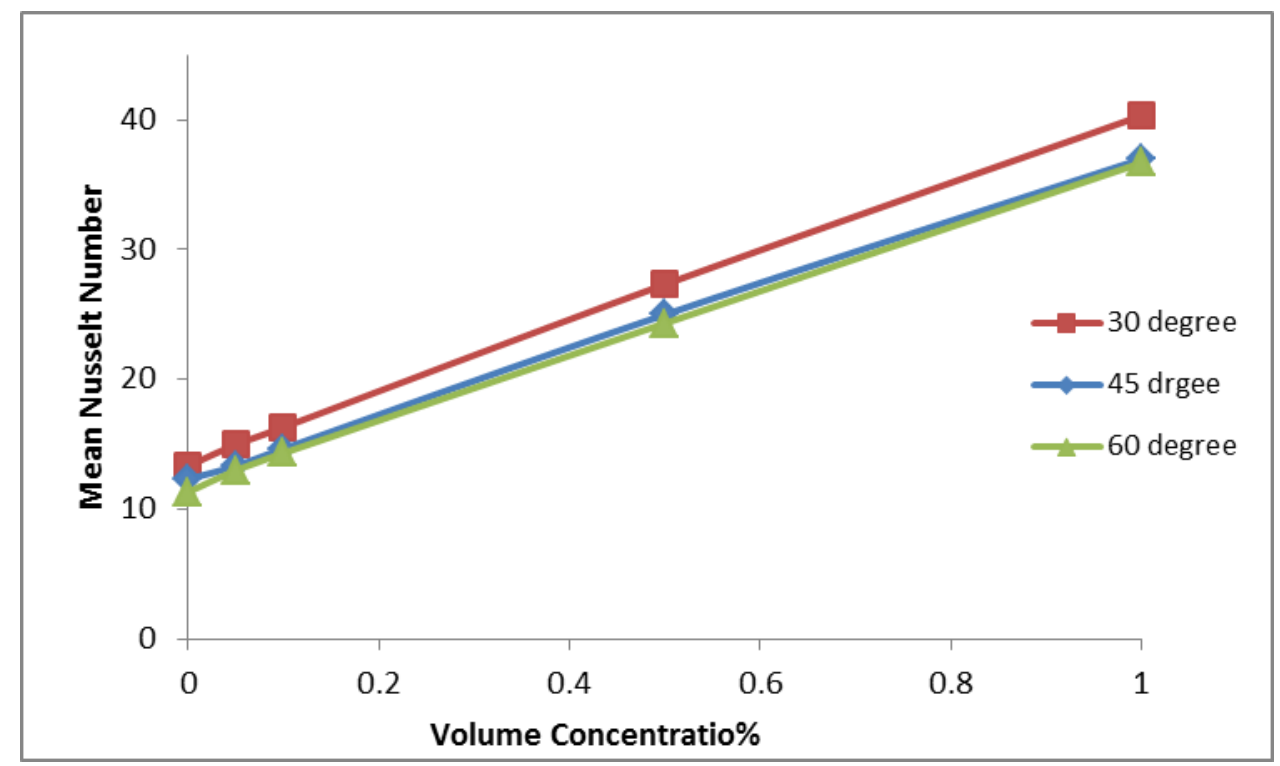

Fig. 9. Effect of inclination angle on mean Nusselt number at different volume fractions

\section{Conclusions}

In this study, the effective heat transfer enhancement and variation of inclination angle have been studied for single tube evacuated solar collector. TiO2-water nanofluid was employed into the collector throughout the study. The present result demonstrated that addition of TiO2-nanoparticles produced a reasonable Heat transfer enhancement in comparison with conventional heat transfer fluid (water). Heat transfer enhancement increases with increasing volume fraction of $\mathrm{TiO}_{2}$ nanoparticles. Nusselt number enhancement was common at inclination angle of $30^{\circ}$, therefore, enhancement of $25.6 \%$ was found at volume fraction $0.1 \%$ while increasing the volume fraction result in a more than $100 \%$ enhancement with respect to water. The influence of inclination angle has indicated that the maximum Nusselt number and velocity are found at the smallest angle of $30^{\circ}$. Hence, inclination angle is an effective parameter for nanofluid filled in single tube evacuated solar collector. Moreover, the CFD model was validated against a PIV measurement. Good agreement was achieved between the simulation and experiment; comparisons were made qualitatively and quantitatively in order to visualized the flow structure in terms of the following parameters: velocity profile, thermal stratifications, temperatures and overall nature of the flow behaviour as it leaves the tube opening and rises up to the reservoir tank. Finally, the result have provided us with self- 
confidence in using the CFD analysis to model a single tube evacuated solar collector using nanofluid subjected to free convection in thermosyphon.

\section{Acknowledgement}

This research was funded by a grant from Takasago Thermal Engineering Ltd (Grant no. 4B314) and Universiti Teknologi Malaysia for supporting this research activity.

\section{References}

[1] Hayek, Michel, Johnny Assaf, and William Lteif. "Experimental investigation of the performance of evacuated-tube solar collectors under eastern mediterranean climatic conditions." Energy procedia 6 (2011): 618-626.

https://doi.org/10.1016/j.egypro.2011.05.071

[2] Lamnatou, Chr, E. Papanicolaou, V. Belessiotis, and N. Kyriakis. "Experimental investigation and thermodynamic performance analysis of a solar dryer using an evacuated-tube air collector." Applied energy 94 (2012): 232-243. https://doi.org/10.1016/j.apenergy.2012.01.025

[3] Xu, Li, Zhifeng Wang, Guofeng Yuan, Xing Li, and Yi Ruan. "A new dynamic test method for thermal performance of all-glass evacuated solar air collectors." Solar energy 86, no. 5 (2012): 1222-1231.

https://doi.org/10.1016/j.solener.2012.01.015

[4] Kim, Yong, and Taebeom Seo. "Thermal performances comparisons of the glass evacuated tube solar collectors with shapes of absorber tube." Renewable Energy 32, no. 5 (2007): 772-795. https://doi.org/10.1016/i.renene.2006.03.016

[5] Nalamwar, G. C., N. R. Kannake, and S. S. Sontakke. "Study and fabrication of vacuum tube collector solar water heater." International Journal of Engineering and Innovative Technology (IJEIT) 2, no. 1 (2012): 220-224.

[6] Morrison, G. L., I. Budihardjo, and M. Behnia. "Water-in-glass evacuated tube solar water heaters." Solar energy 76 , no. 1-3 (2004): 135-140.

https://doi.org/10.1016/i.solener.2003.07.024

[7] Morrison, G. L., I. Budihardjo, and M. Behnia. "Measurement and simulation of flow rate in a water-in-glass evacuated tube solar water heater." Solar Energy 78, no. 2 (2005): 257-267. https://doi.org/10.1016/i.solener.2004.09.005

[8] Gaa, F. O., M. Behnia, and G. L. Morrison. "Experimental study of flow ratets through inclined open thermosyphons." Solar Energy 57, no. 5 (1996): 401-408. https://doi.org/10.1016/S0038-092X(96)00110-7

[9] Gao, Y., R. Fan, X. Y. Zhang, Y. J. An, M. X. Wang, Y. K. Gao, and Y. Yu. "Thermal performance and parameter analysis of a U-pipe evacuated solar tube collector." Solar energy 107 (2014): 714-727. https://doi.org/10.1016/j.solener.2014.05.023

[10] Mishra, Dilip, and N. K. Saikhedkar. "A study and theoretical analysis of evacuated tube collectors as solar energy conversion device for water heating." Advance Physics Letter 1, no. 3 (2014): 26-35.

[11] Ma, Liangdong, Zhen Lu, Jili Zhang, and Ruobing Liang. "Thermal performance analysis of the glass evacuated tube solar collector with U-tube." Building and Environment 45, no. 9 (2010): 1959-1967. https://doi.org/10.1016/i.buildenv.2010.01.015

[12] Ayompe, L. M., and Aidan Duffy. "Thermal performance analysis of a solar water heating system with heat pipe evacuated tube collector using data from a field trial." Solar Energy 90 (2013): 17-28. https://doi.org/10.1016/i.solener.2013.01.001

[13] Kumar, Ashish, Sanjeev Kumar, Utkarsh Nagar, and Avadhesh Yadav. "Experimental study of thermal performance of one-ended evacuated tubes for producing hot air." Journal of Solar Energy 2013 (2013): 1-6. https://doi.org/10.1155/2013/524715

[14] Paradis, Pierre-Luc, Daniel R. Rousse, Stéphane Hallé, Louis Lamarche, and Guillermo Quesada. "Thermal modeling of evacuated tube solar air collectors." Solar Energy 115 (2015): 708-721. https://doi.org/10.1016/i.solener.2015.03.040

[15] Zhang, Hui, Hui-Jiuan Chen, Xiaoze Du, and Dongsheng Wen. "Photothermal conversion characteristics of gold nanoparticle dispersions." Solar Energy 100 (2014): 141-147. https://doi.org/10.1016/i.solener.2013.12.004

[16] Said, Z., M. A. Sabiha, Rahman Saidur, A. Hepbasli, Nasrudin Abd Rahim, Saad Mekhilef, and T. A. Ward. "Performance enhancement of a flat plate solar collector using titanium dioxide nanofluid and polyethylene glycol dispersant." Journal of Cleaner Production 92 (2015): 343-353. https://doi.org/10.1016/i.jclepro.2015.01.007 
[17] Nasrin, Rehena, Salma Parvin, and M. A. Alim. "Heat transfer by nanofluids through a flat plate solar collector." Procedia Engineering 90 (2014): 364-370.

https://doi.org/10.1016/i.proeng.2014.11.863

[18] Liu, Zhen-Hua, Ren-Lin Hu, Lin Lu, Feng Zhao, and Hong-shen Xiao. "Thermal performance of an open thermosyphon using nanofluid for evacuated tubular high temperature air solar collector." Energy Conversion and Management 73 (2013): 135-143. https://doi.org/10.1016/i.enconman.2013.04.010

[19] Mahendran, M., G. C. Lee, K. V. Sharma, A. Shahrani, and R. A. Bakar. "Performance of evacuated tube solar collector using water-based titanium oxide nanofluid." Journal of Mechanical Engineering and Sciences 3 (2012): 301-10. https://doi.org/10.15282/jmes.3.2012.6.0028

[20] Zainab Ali Ibrahim, Qusay Kamil Jasim, and Adnan Mohammed Hussein. "The Impact of Alumina Nanoparticles Suspended in Water Flowing in a Flat Solar Collector." Journal of Advanced Research in Fluid Mechanics and Thermal Sciences 65, no. 1 (2020): 1-12.

[21] Lu, Lin, Zhen-Hua Liu, and Hong-Sheng Xiao. "Thermal performance of an open thermosyphon using nanofluids for high-temperature evacuated tubular solar collectors: Part 1: Indoor experiment." Solar energy 85, no. 2 (2011): 379-387. https://doi.org/10.1016/j.solener.2010.11.008

[22] Azizi, Mehdi, Maryam Hosseini, Samira Zafarnak, Mehdi Shanbedi, and Ahmad Amiri. "Experimental analysis of thermal performance in a two-phase closed thermosiphon using graphene/water nanofluid." Industrial \& Engineering Chemistry Research 52, no. 29 (2013): 10015-10021. https://doi.org/10.1021/ie401543n

[23] Al-Mashat, Saad M. Saleh, and Abbas Ahmed Hasan. "Evaluation of convective heat transfer and natural circulation in an evacuated tube solar collector." Journal of Engineering 19, no. 5 (2013): 613-628.

[24] Hussain, Hashim A., Qusay Jawad, and Khalid F. Sultan. "Experimental analysis on thermal efficiency of evacuated tube solar collector by using nanofluids." Sol Energy 4 (2015): 19-28.

[25] Li, Yang, Hua Qing Xie, Wei Yu, and Jing Li. "Investigation on heat transfer performances of nanofluids in solar collector." In Materials Science Forum, vol. 694, pp. 33-36. Trans Tech Publications Ltd, 2011. https://doi.org/10.4028/www.scientific.net/MSF.694.33

[26] Goudarzi, K., F. Nejati, E. Shojaeizadeh, and SK Asadi Yousef-abad. "Experimental study on the effect of pH variation of nanofluids on the thermal efficiency of a solar collector with helical tube." Experimental Thermal and Fluid Science 60 (2015): 20-27. https://doi.org/10.1016/i.expthermflusci.2014.07.015

[27] Sato, André Issao. "Análise numérica de um coletor solar de tubo evacuado." (2012): 76-f.

[28] Budihardjo, Indra, Graham L. Morrison, and Masud Behnia. "Natural circulation flow through water-in-glass evacuated tube solar collectors." Solar Energy 81, no. 12 (2007): 1460-1472. https://doi.org/10.1016/j.solener.2007.03.002

[29] Sparrow, Eo M. "Leminar Free Convection from a Vertical Plate with Uniform Surface Heat Flux." J. Heat Transfer 78 (1956): 435-440.

[30] Jaluria, Yogesh. "Natural convection, heat and mass transfer." In Unknown Host Publication Title. Pergamon Press, 1980.

[31] Issa, Raad I. "Solution of the implicitly discretised fluid flow equations by operator-splitting." Journal of computational physics 62, no. 1 (1986): 40-65. https://doi.org/10.1016/0021-9991(86)90099-9

[32] Abu-Nada, Eiyad, and Hakan F. Oztop. "Effects of inclination angle on natural convection in enclosures filled with Cu-water nanofluid." International Journal of Heat and Fluid Flow 30, no. 4 (2009): 669-678. https://doi.org/10.1016/j.ijheatfluidflow.2009.02.001 